\title{
Jevons' paradox and a tax on aviation to prevent the next pandemic*
}

\author{
Salvador Pueyo ${ }^{\mathrm{a}, \mathrm{b}, \uparrow}$ \\ ${ }^{a}$ Dept. Evolutionary Biology, Ecology, and Environmental Sciences, \\ Universitat de Barcelona, Av. Diagonal 645, 08028 Barcelona, \\ Catalonia, Spain \\ ${ }^{b}$ Research \& Degrowth, C/ Trafalgar 8 3, 08010 Barcelona, Catalonia, Spain
}

\begin{abstract}
How is it possible that, in an era of unprecedented medical progress, humanity is once again caught in a major pandemic? Several lines of evidence suggest that advances in infectious diseases control facilitate the development of major urban centers, global highspeed transportation, industrial animal farming and ecosystem destruction. In turn, all of these are well known to favor such diseases, thus reproducing the same kind of dynamic observed in resource consumption and known as Jevons' paradox. Such economic developments compel health systems to develop continuously just to maintain what had already been achieved, which, furthermore, becomes more difficult under neoliberal policies. The process involves massive cost-shifting to society from firms in, e.g., the aviation or meat sector, which materializes intermittently in disasters such as the COVID-19 pandemic. A proposal is presented to prevent comparable events in the future, with two parts. First, a global fund with base funding from an internationally-agreed tax on aviation, devoted to upgrading health systems and to programs to tackle sources of emerging infectious diseases, especially wild animal trade. Second and no less important, a global agreement to fundamentally transform agri-food systems. This plan should be accompanied by redoubled attention to various dimensions of global change.
\end{abstract}

Keywords: COVID-19; Globalization; Air travel; Meat consumption; Pandemic politics; Degrowth.

\section{Introduction}

How is it possible that, in an era of unprecedented medical progress, humanity is once again caught in a major pandemic? This paper suggests a systemic explanation and outlines a plan to prevent a comparable if not even more harmful (e.g., Mermel, 2005) pandemic in the future.

${ }^{*}$ Copyright 2020 Salvador Pueyo. This work is made available in SocArXiv under the Creative Commons Attribution 4.0 International Public License. https://doi.org/10.31235/osf.io/vb5q3

${ }^{\dagger}$ E-mail: spueyo@riseup.net 
Jevons' paradox, also known as rebound effect, takes place when greater efficiency in the use of some given natural resource stimulates growth in the economic activities that consume the resource, which offsets the potential benefit for sustainability (Alcott, 2005). However, resource use is not, probably, the only aspect of sustainability to which this logic applies (Alcott, 2005; Schneider, 2008), and, in particular, it could be crucial to understand the evolution of epidemic risk: As the author noted in Pueyo (2014, p. 3452), advanced ways to fight against infectious diseases have eased the development of dense urban conglomerates, industrial farms and quick transport all over the world, which represents an excellent culture medium for any infectious agent able to overcome the current protections. The novelties in this paper are: the detailed justification of the feedbacks implied by this assertion; the suggestion that, to some extent, also ecosystem destruction is integrated in this dynamic; the conceptual connection to Jevons' paradox and also to the Red Queen phenomenon; the introduction of the distributive dimension of these processes, noting that they involve massive cost-shifting; and a policy proposal to escape the epidemiological Jevons' paradox.

In infectious diseases, feedbacks offsetting progress preceded the emergence of Jevons' paradox in all of its variants, as apparent from thousands of millions of years of arms race between pathogens and hosts, a race that is considered a powerful motor of evolution and diversification. This phenomenon is called Red Queen, because, like the character of Alice through the Looking Glass that gives it its name, both hosts and pathogens need all the running you can do, to keep in the same place (Decaestecker and King, 2019). In modern societies, this race has encountered at least three important novelties. First, progresses in sanitation, medicine and health systems gave a boost to (human) hosts, and allowed us not just to keep in the same place but also to gain advantage in the race, decreasing substantially the presence of infectious diseases in part of the world. This is not the end of the race, however, with bacteria developing resistance to antibiotics (Laxminarayan et al., 2016; Holmes et al., 2016) and these and other emerging infectious agents replacing those that were under control (Jones et al., 2008). Second, the Red Queen met Jevons: the evidence synthesized in sec. 2 suggests that the improved sanitary conditions opened the door for growth imperatives and driver: ${ }^{1}$ (Richters and Siemoneit , 2019) to lead to the expansion of economic activities and patterns of organization that favor the origination and propagation of infectious diseases and that, otherwise, would have probably been constrained by these same diseases. In other words, human society is in a race not just against pathogens (Red Queen) but also against itself (Jevons), so health systems need to run even more to keep in the same place, let alone to stay ahead of pathogens. Third, in recent decades, the hegemony of neoliberal policies resulted in health systems leaving the race in many countries (Ottersen et al., 2014). These are the developments that, arguably, set the stage for the COVID-19 pandemic.

Section 2 synthesizes the evidence for an epidemiological Jevons' paradox. Section 3 discusses the distributive issues involved. Section 4 puts forward a specific policy proposal to escape the paradox (which, however, would be sound even if there were no such paradox). The paper ends with the Discussion.

\footnotetext{
${ }^{1}$ In the terminology used by Richters and Siemoneit (2019), growth imperatives are conditions that create the need for a given agent to increase its production or consumption to avoid existential consequences, while other, less peremptory motivations for growth are subsumed under the concept of growth drivers. For a firm, the growth imperative and the growth driver par excellence are, respectively, competition (when this compromises the firm's survival) and the pursuit of profit (as an end in itself). Other growth imperatives and drivers may exist for consumers and for countries.
} 


\section{Foundations for an epidemiological Jevons' paradox}

This section synthesizes the evidence in support of an epidemiological Jevons' paradox as described in the Introduction, with each subsection referring to a different economic sector, pattern or process. Of course, the mechanisms of the bottom up feedback exerted by resource availability in the original Jevons' paradox (Alcott, 2005) differ from those of the top down $2^{2}$ feedback exerted by infectious diseases, but they are suggested to have a comparable role in their interplay with growth drivers and imperatives.

\section{$2.1 \quad$ Urbanization}

The suggestion in this subsection is that growth imperatives and drivers favor the agglomeration of people in cities but that this process was traditionally counteracted by the greater prevalence of infectious diseases in such areas, before the advent of modern sanitation and health systems. Part of this old dynamics resurged with the COVID-19 pandemic, which exhibits a greater basic reproductive number in larger cities (Stier et al., 2020).

It is well known that, in simple epidemiological models, infectious diseases can exert a negative feedback on local abundance (Anderson and May, 1979). Even though it is not straightforward to observe this feedback in nature because it is most often intertwined with other feedbacks, there is evidence that it has much impact on some animal populations (Frick et al., 2015). Furthermore, according to epidemiological models, since a high case-fatality rate hampers the propagation of diseases, lethal pathogens would only survive and become endemic where there is a large availability of potential hosts (Anderson and May, 1979). This led to the conjecture that most deadly infectious diseases needed the previous appearance of cities to become established (Dobson and Carper, 1996).

Before the $20^{\text {th }}$ century, urban mortality clearly exceeded rural mortality in Europe and elsewhere (Storey, 1985). Even though the chemical pollution of $19^{\text {th }}$ century industrial cities played a role, it is widely accepted that the main cause were infectious diseases, in the $19^{\text {th }}$ century (Hanlon and Tian, 2015) and especially before (Walter and DeWitte, 2017). Such diseases were favored by the agglomeration of people and also by the accumulation of organic waste (Walter and DeWitte, 2017). According to estimates for 1700-1750, in European cities mortality was $25 \%$ greater than natality, but they sustained their population and even grew by absorbing immigration from rural areas, thus acting as sinks for people. Urban mortality gradually decreased, and dropped below natality in the 19th century, but it remained greater than in rural areas (Jewad et al., 2015). Detailed analyses of $19^{\text {th }}$ century English demographic data detect a strong positive correspondence between the size of municipalities and their mortalities, justifying the appellative killer cities (Hanlon and Tian, 2015). In that period the (demographic) natural growth rate of cities was still modest, but they kept growing actively by absorbing immigration (Jewad et al., 2015).

The higher intensity of interactions permitted by high population densities facilitates disease propagation (Bettencourt et al., 2007; Alirol et al., 2011) but also economic activity. There is

\footnotetext{
${ }^{2}$ These are ecological terms. Top-down regulation of the population of a given species is exerted by other species in higher trophic levels, while bottom-up regulation results from the limited abundance of species in lower levels or of abiotic resources. Here these terms are applied to economic activities and structures rather than to population.
} 
a strong positive correspondence between city size and various indicators of economic activity and growth, with cities being often described as engines of economic growth (Bettencourt et al., 2007). This is a fundamental reason why cities have traditionally attracted immigration. However, the realization of this potential for economic growth needs growth imperatives or at least growth drivers, so it is these that ultimately pull people toward cities, aided on occasions by social, cultural and political factors. Since there has always been an economic niche for workers in rural areas, especially in the primary sector, socioeconomic factors must have created a tendency toward some given proportion of urban and rural dwellers (ignoring, for the moment, epidemiology). This socioeconomic attractor has indeed changed through time, notably because of changes in agricultural productivity and other transformations in the countryside which added a rural push to the urban pull (Jedwab et al., 2015). Whatever the urban share of population that would have resulted from the socioeconomic attractor at some given point of history, however, the share resulting from a more realistic attractor, with epidemiology included, must have been substantially lower when referring to historical periods in which, e.g., urban mortality exceeded urban natality by $25 \%$. For this tentative conclusion not to be valid, the degree of inertia in the place of residence should have been negligible (so migratory movements would have erased, with no delay, the impact of differences in natural demographic growth rate on the spatial distribution of population) and the dark prospects for health and survival in cities should have exerted no dissuasion on potential immigrants. A piece of evidence consistent with the tentative conclusion is historians' interpretation that Britain's problem in the $19^{\text {th }}$ century (when urban natural growth was no longer negative but still modest) was excess labor demands centered in cities where the rates of natural increase were lowest (Williamson, 1990: p. 5). In other words, before the $20^{\text {th }}$ century, urban population share must have resulted largely from a tension between economic growth imperatives and drivers on the one hand and infectious disease on the other, and advances in the fight against diseases must have freed growth imperatives and drivers to promote large-scale urbanization.

A comparison between $19^{\text {th }}$ century English and contemporary Chinese cities showed that the relation between city size and mortality had inverted (Hanlon and Tian, 2015), so, at that point of space and time, urban expansion would not have offset the health benefits brought about by the new capabilities to manage diseases. In contrast, the nexus between urbanization and infectious disease spread remains strong in most lower income countries' megacities (whose expansion is, however, mostly driven by the rural push) (Alirol et al., 2011). More generally, large cities all over the world remain especially vulnerable to new, emerging diseases during the period in which no effective treatment is available. A significant correlation with city size had already been observed for AIDS (Bettencourt et al., 2007) and has now been found for COVID-19 (Stier et al., 2020).

In sum, urbanization appears to play an important role in the epidemiological Jevons' paradox. It is, however, a double-edged sword, because it also provides opportunities in terms of economies of scale in health care (as in other fields, Xue, 2014). Because of this, while submitting that the epidemiological Jevons' paradox merits inclusion in future spatial planning, the more specific policy proposals in this paper (sec. 4) focus on other facets of the economy, treated in the coming subsections. 


\subsection{Connectivity and transportation}

While the agglomeration of people in large cities favors interactions (and therefore the spread of infectious diseases as well as economic activity) (Bettenecourt et al., 2007), these also depend on subtler aspects of connectivity in social networks, and especially on the connectivity among cities mediated by transportation. There are well-known model systems in which connectivity and fluctuations are mutually regulated ${ }^{3}$ (Pruessner, 2012). It has been suggested that these apply to the interaction between social networks and epidemics, based on (weak) evidence from islands (Rhodes et al., 1997) reached intermittently by infectious diseases (these specific models do not apply to endemic diseases, but these could equally be subject to a negative feedback with connectivity). In medieval Europe, the Black Death affected more severely the cities that were better connected (Gómez and Verdú, 2017; however, this study did not separate the effect of city size), which must have exerted a negative feedback on connectivity among people by selectively reducing the population of such cities.

In the contemporary, globalized world, particularly important for connectivity is the intensity and speed of long range transportation of people, livestock and products. Among the various carriers involved, aviation merits special attention. Its yearly growth rates of $6-8 \%$ in recent years (IATA, 2019a, p. 3) and the revenues approaching a trillion dollars (IATA, 2019b) imply that growth imperatives or drivers are strong in this case, as is the role of aviation in spreading infectious diseases (Wang and $\mathrm{Wu}, 2018$ ). To have a notion of how disease propagation has changed through history, let us consider, again, the case of the Black Death. At an estimated speed of 330-400 $\mathrm{km} \mathrm{y}^{-1}$, it probably took a decade or more for this epidemic to move from Central Asia to Europe (Schmid et al., 2015). Thereafter it accelerated to more than $1000 \mathrm{~km}$ $\mathrm{y}^{-1}$ (Schmid et al., 2015), which is considered an exceptional speed (Cohn, 2008), and spread over most of Europe in only three years (Schmid et al., 2015). Ship journeys covering long distances took place and were quicker, but infrequent. At such speed and frequencies but with modern methods to deal with diseases, COVID-19 would have hardly left Hubei. However, aviation moves pathogens from end to end of the world overnight. Other means of transportation also participate, but aviation is so crucial that it is the only factor considered in state-of-the-art models of long-range propagation of diseases (Wang and $\mathrm{Wu}, 2018$ ).

Being clear that the proliferation of aviation did offset much of the benefit that could have been gained from progress in sanitation and health systems, the remaining question is whether the other part of the feedback also exists, i.e., if aviation is adversely affected by infectious diseases and owes its prominence to the current capacities to deal with such diseases. The impact of COVID-19 on aviation is extreme and visible. By mid April, 2020, worldwide flights had decreased by $80 \%$, and much more if U.S. and Asia domestic markets are left aside (Pearce, 2020a), with the recovery expected to be slow (Pearce, 2020b). The theoretical implications of this collapse are not straightforward, because much of the impact is due to measures taken by the very governments that are rescuing or committing to rescue the sector. However, many airlines were already severely impacted before being affected by governmental decisions, because of passengers' fear, according to journalistic sources (Isidore, 2020), and this fear would have increased if the pandemic's rate of growth had not been reduced by governments' measures. On the other hand, this was a short-term reaction, which could moderate in a scenario where a high risk of contagion of severe infectious disease were no longer a novelty but the norm (e.g.,

\footnotetext{
${ }^{3}$ See Pueyo (2014) about the relevance of such models for ecological economics.
} 
in a post-antibiotic era, sec. 2.3p. While any discussion on a scenario like this is necessarily speculative, a number of permanent changes discouraging air transportation appear plausible, especially at destinies, such as: more restrictive admission norms at entry points, and quarantines being demanded with some frequency; some social avoidance of travelers; higher disease incidence in urban regions hosting especially active airports (like well connected cities during the Black Death; Gómez and Verdú, 2017), thus losing some vigor and appeal. All of these would be components of the suggested negative feedback.

\section{$2.3 \quad$ Livestock}

Another highly relevant economic sector that has undergone substantial growth in the $20^{\text {th }}-21^{\text {st }}$ centuries (largely for luxury consumption, associated to GDP growth; FAO, 2006, p. 9) is the production of meat and other animal products. While wild mammals are in serious regression, the total mammal biomass has more than quadrupled through human history, with $35 \%$ being human biomass and $59 \%$ livestock (Bar-On et al., 2018). Therefore, 7.7 billion people make up just $38 \%$ of the mammal mass (or 36\% of the mammal and bird mass; Bar-On et al., 2018) participating in modern societies, which (animal ethics aside) is a problem not only because these animals need to eat $t^{4}$ and excrete with the consequent impacts on resources and the environment (Poore and Nemecek, 2018; IPCC, 2019, ch. 5, p. 488), but also because (details below) (1) this multiplies the effective population susceptible to shared or shareable pathogens, (2) some features of the industrial methods applied to sustain so much livestock magnify disease spread, (3) in part to avoid such spread, industrial livestock production is heavily medicalized, which leads to the evolution of antibiotic resistance in bacteria, and (4) diseases transmitted from other species are especially dangerous because, often, people's immune systems and societies' health systems are unprepared. The features of industrial farming magnifying disease spread include: high numbers of animals per facility; high densities; early weaning which decreases immunity (Bech et al., 1983); and intensive transportation of animals between farms and to slaughterhouses, often at long distances and in stressful conditions (observed to induce a quick multiplication of some pathogens; Barham et al., 2002). The resulting animal products are also transported at increasing distances (e.g., Boqvist et al. (2014) reported that EU meat imports had nearly duplicated in one decade).

Out of 335 emerging infectious diseases reported between 1940 and 2004, 43\% were found to have originated in wildlife and $17 \%$ in other vertebrates (i.e., basically, livestock), whereas no zoonotic source was identified in the other $40 \%$ (Jones et al., 2008). While the ongoing ecological disruption multiplies the transfer of diseases from wildlife (secs. 2.4-2.5), many important diseases are thought to have originated historically in animal agriculture, and, apparently, the comparatively low diversity of pathogens in pre-Columbian America was due to the limited presence of this activity (Wolfe et al., 2007). Animal food consumption is involved in the two zoonotic categories and is seen as the most frequent checkpoint in the transfer of novel pathogens to humans (Kock et al., 2020). The three categories are not fully separable, for at least three reasons. First, some relevant species normally thought of as wild are also farmed (Kan et al., 2005). Second, transmission chains often involve more than one species, with ordinary livestock

\footnotetext{
${ }^{4}$ Since animals need to dissipate energy, only a small fraction of the resources fed to livestock reaches human consumers (Schader et al., 2015).
} 
often playing the role of bridge or amplifying hosts for pathogens originating in wildlife (Kock et al., 2020). Third, without need of directly causing outbreaks in humans, antibiotic resistant bacteria originating in livestock can transmit their resistance genes to other bacteria infecting humans (Holmes et al., 2016).

Resistance to antibiotics is an area in which the Red Queen dynamic (sec. 1) is especially active within modern societies. $21 \%$ of the emerging diseases reviewed by Jones et al. (2008) were caused by antimicrobial-resistant bacterial strains, with an increasing trend. One decade ago, an estimated 25,000 people per year were killed by multidrug-resistant bacteria in the EU alone (ECDC and EMEA, 2009), and the problem tends to worsen (ECDC and EMEA, 2009; Laxminarayan et al., 2016; Holmes et al., 2016). Bacterial evolution has outpaced the development of new antibiotics for long, with experts fearing a post-antimicrobial or post-antibiotic era, in which, e.g., medical interventions needing aseptic conditions would no longer be possible (Laxminarayan et al., 2016). This serious but underappreciated dimension of unsustainability results from the use and overuse of antibiotics in human patients and animal agriculture (Laxminarayan et al., 2016; Holmes et al., 2016), including pisciculture (Holmes, 2016). In high income countries, the ratio between agricultural and medical use of antibiotics is close to nine (Rohr et al., 2019). Resistance evolves not only within hosts but also in the environment, due to antibiotics in effluents (Laxminarayan et al., 2016; Holmes, 2016).

Because of its intimate association to the availability of antibiotics and other veterinary treatments, industrial farming is a sector in which the epidemiological Jevons' paradox is especially apparent. However, also in this sector there are worth-considering subtleties. The case of Denmark, described by Wielinga et al. (2014), is revealing because of its early changes in production practices. In Denmark there is a strong presence of industrial farming, with, among other livestock, 111 million broiler chickens and 29 million pigs for 5 million people. Until the mid nineties, antibiotics were applied intensively, as in most western countries, and, as is commonplace, they were used not only to cure animals' disease but also for prevention and even as growth stimulants. This is attributed to farmers' perception that they were needed to avoid widespread disease in the conditions of industrial farming, as well as to veterinarians' vested interest as sellers of the antibiotics that they prescribed (in other words, to growth imperatives or profit motives in these two sectors). However, immediately after new scientific findings in those years, both the farming sector (which is special in this country because of its co-operative nature) and the government reacted and adopted measures to reduce their application. Later, in 2006, the use of antibiotics as growth stimulants was outlawed in the whole EU (a minimal measure still not adopted in the U.S. and other countries). In Denmark, $60 \%$ of antibiotics, which were not used to cure disease, were eliminated, with the help of alternative prophylactic procedures, and with only $1 \%$ increase in production costs (Wielinga et al., 2014). However, the other $40 \%$ remained, and, after the initial decoupling, growth in meat production was again coupled to growth in antibiotic consumption (figure 4 in Wielinga et al., 2014). This suggests that greater reductions would have greater economic impacts, or would even make intensive production inviable. The notion that contemporary intensive animal farming would be difficult to conceive without at least some use of antibiotics is implicit in much of the literature: e.g., Rohr et al. (2019) attribute their use to the effort to prevent catastrophic disease-associated losses. The epidemiological Jevons paradox affects the total consumption of animal products, because it would not be possible to simply replace intensive by extensive farming, given the limited carrying capacity of each territory. Ex- 
tensive beef production is already a motor of tropical deforestation (Fearnside, 2017) (and also subject to the epidemiological Jevons' paradox; sec. 2.4). A detailed comparison of two global food production scenarios for 2050, business as usual and a scenario with livestock fed only from grassland and by-products of food production, revealed that animal product consumption would be at least $70 \%$ lower in the second case (Schader et al., 2015). In a nutshell, animal-based food production is a sector in which the epidemiological Jevons' paradox is particularly strong, apparent and dangerous, and is tightly coupled to the Red Queen dynamic.

\subsection{Ecosystem destruction}

The origin of more than $40 \%$ emerging infectious diseases has been traced to wildlife, as noted in sec. 2.3, and there is an increasing trend in the rate of transfer of novel diseases from wildlife to humans (Jones et al., 2008). In particular, the consumption of some wild mammal is seen as a specially likely origin for COVID-19 (Andersen et al., 2020), which exemplifies the hazard inherent to wild animals' exploitation and trade (Johnson et al., 2020). It is also established that land clearing and habitat fragmentation carries risk of emerging diseases (IPBES, 2019, p. 22), because it removes protective covers and creates active interfaces between society and previously remote ecosystems, whose microbial and viral communities had been virtually isolated from the global networks of dissemination until the arrival of the frontier of deforestation (Rohr et al., 2019; Johnson et al., 2020), besides forcing animals from cleared lands to move elsewhere (Wu et al., 2020). (Conversely, in such interfaces there is transfer of diseases from humans and domesticated animals to wildlife, which can devastate wild populations; Rohr et al., 2019). There is evidence that habitat protection reduces disease risk (Wu et al., 2020). The synergy between land clearing and wild animal consumption is especially dangerous, lying, e.g., behind the origin of ebola (Rulli et al., 2017).

Even though it is not claimed in this paper that the epidemiological Jevons paradox is always involved in ecosystem destruction, there is evidence that it is in many instances. Infectious diseases are thought to have prevented the European colonization of the Old World tropics for centuries, as well as the French completion a Panama Canal (Wolfe et al., 2007). The ongoing colonization of Amazonia is precisely one of the few contexts in which a negative feedback involving infectious diseases has been explicitly studied. While it is well known that rainforest colonization results, initially, in high incidence of malaria, MacDonald and Mordecai (2019) also found that this disease slows down colonization. Furthermore, Amazonia is precisely a region where deforestation is tightly linked to the production of beef and feedstock for the global market (Fearnside, 2017). From the conclusions of sec. 2.3 follows that the epidemiological Jevons' paradox is an indirect motor of deforestation for feed production. In situ beef production is directly involved in the paradox, because these animals are heavily medicalized to resist local diseases (Meirelles Filho, 2004, p. 156).

\subsection{Other factors}

Besides the factors treated in sec. 2.1,2.4, there are other ways in which economic activities contribute to epidemic risk, but for which no role of the epidemic Jevons' paradox was identified, if the general impact of diseases on economic activity is left aside. Two of these are poised to gaining much weight in the future. First, many economic activities impact climate. Different 
diseases have different weather optima and are therefore affected differently by climate change, but a more general impact is to compel animals to shift their geographic distributions, thus creating opportunities to transfer pathogens to humans or other species from which they used to be isolated (Carlson et al., 2020). Shifts in the distribution of several bat species in China, including from the Rhinolophus genus, whose involvement in COVID-19 is suspected (Andersen et al., 2020), have been attributed to climate change (Wu, 2016), which is far from sufficient to conclude a causal connection between climate change and COVID-19 but serves as warning. There are even fears that climate change could release ancient pathogens frozen in permafrost as this melts (Legendre et al., 2015). Second, some economic activities involve genetic engineering, a technology whose unrestrained use could potentially result in the accidental or deliberate release of novel pathogens (Green et al., 2019). The study by Andersen et al. (2020) showing that SARS-CoV-2 is unlikely to have been engineered serves, however, to illustrate the hazards posed by this technology.

\section{Distributive issues}

\subsection{Cost shifting}

In sec. 2 the epidemiological Jevons' paradox was presented just in terms of aggregate variables. However, it also implies that progresses whose primary purpose is to benefit everybody's health are transmuted into benefits for certain economic activities and the actors involved in such activities, which, therefore, consciously or unconsciously, are engaged in systematic cost-shifting 5 toward the rest of society. These include major firms in sectors such as aviation of meat. Denmark farmers are a reported example of economic agents becoming aware of the costs that they were transferring and taking some steps to reduce them, but this is an exceptional case (which has been attributed to the co-operative nature of the sector in that country; Wielinga et al., 2014), and their remedy was partial (sec. 2.3).

Long-haul aviation is an instance in which the contrast is extreme also on the demand side, i.e., in the dissociation between who benefit as consumers ${ }^{6}$ and who pays the costs. The share

\footnotetext{
${ }^{5}$ The concept of cost-shifting, widely used in ecological economics, has its roots in K.W. Kapp's writings on social costs (Spash, 2019), i.e., harmful effects and inefficiencies that must have two characteristics. It must be possible to avoid them and they must be part of the course of productive activities and be shifted to third persons or the community at large (Kapp, 1978 [1963], p. 14). The load of pandemic risk involved in the productive activities listed in sec. 2 not only is shifted to the community at large but also satisfies the condition of being, in part, avoidable (sec. 44), so it is also a social cost sensu Kapp. He also wrote the term 'social costs' covers all direct and indirect losses sustained by third persons or the general public as a result of unrestrained economic activities. These social losses may take the form of damages to human health (...) (Kapp, 1978 [1963], p. 13), and included costs that are the result of the interaction of a great number of factors which make the process of causation a complex and frequently a cumulative one (Kapp, 1978 [1963], p. 13). When discussing cost-shifting, he gives an example whose parallel to pandemics is straightforward: In other cases, such as the greater frequency and severity of floods resulting from soil erosion, the social losses are catastrophic in character and appear to be the result of 'force majeur', although actually they are caused or at least aggravated by the productive activities of entrepreneurs (Kapp 1978 [1963], p. 267).

${ }^{6}$ This does not mean that customers who flew in the pre-COVID-19 must be blamed for this problem, because, in most of the information sources reaching non-specialized audiences, pandemic risks were either ignored or portrayed as remote or under control, and the minority within this minority who were aware of the problem might have generally seen as futile to change their behavior in isolation. A small fraction of flights may also be
} 
of the global population participating in international air travel in any given year is probably $<4 \%$ (Appendix A), which is indicative of the small minority participating in long-haul flights (a more relevant figure). Within this group, there are major differences in the frequency of flights. Furthermore, high frequency of international flights is often associated to high income, as can be observed both within (Gössling et al., 2009; Graham and Metz, 2017) and among (Vogel, 2016, p. 75) countries. This is even more apparent when considering the owners of private jets. On the supply side, aviation is a powerful sector with revenues of $\$ 838$ billion and a net profit of $\$ 25.9$ billion in 2019 (IATA, 2019b), in which 5 firms control $20 \%$ international passenger flights (calculated from IATA, 2019a). The major companies benefiting from international freight transportation by air must also be taken into account when the kind of freight carries some epidemiological risk. In short, both on the demand and on the supply sides, long-haul aviation is an activity in which just a minor fraction of the world's population is involved, largely belonging to high income groups. This contrasts with the key role that this activity plays in the spread of pandemics (sec. 2.2). It has been for decades that air transportation data have been the main foundation for analyses of the long-range propagation of diseases (Wang and Wu, 2018), while epidemiologists repeatedly warned of the risk of a major pandemic causing a high mortality (Mermel, 2005). For airlines, profits or growth imperatives have been taking preeminence over the need to prevent such an outcome (and over climate).

With COVID-19, the costs systematically transferred to society by airlines and other companies, initially in the form of risk, have materialized, as of 25 June 2020 and with the pandemic still growing, in the form of 483 thousand deaths officially attributed to the disease (database by Dong et al., 2020) plus an unknown number awaiting attribution, millions of infected people, Herculean unpaid and underpaid (if not unpayable) care work to dampen this impact, social distancing and lockdown affecting most of the world's population with the concomitant psychosocial burden (or even lack of access to essential material goods; HRW, 2020) and an incipient economic depression that will cause much suffering in growth-dependent economies, while many air companies are being rescued with taxpayers' money. In the response to the pandemic, there are even reported instances of generalized police violence against low-class citizens (HRW, 2020) who have never flown and are the least likely to have introduced the disease to their countries. In sum, humanity is witnessing and suffering one of the most massive cost-shifting events ever, without even being aware of it.

\subsection{Inequality and health systems}

While the asymmetric nature of the interactions described throughout this paper creates this intimate association between epidemiological Jevons' paradox and cost-shifting, the specific ways in which the paradox materializes is also affected by other, preexisting distributive problems. These are described briefly because they are already well known. Before the COVID-19 pandemic, infectious diseases had ceased to be perceived as a major cause of mortality in the wealthiest parts of the world but not elsewhere (Alirol et al., 2011). Malnutrition weakens the immune system (Rohr et al., 2019), and insufficient access to health systems is a serious concern in

seen as justified even after factoring-in their epidemiological impact and the more widely known (and, therefore, less often excusable) climatic impact. It is not so readily justifiable for the companies in this sector not to have seriously addressed pandemic risks, because this problem so little known by the general public was however well known by specialists. 
many countries. Underlying such deficiencies there are the structural inequalities of international economic relations (Ottersen et al., 2014), the rich history of boycotts, by high-income countries, to attempts to implement socializing policies in low income countries (Hickel, 2017), and the structural adjustment plans imposed by the IMF in most of the latter countries (Forster et al., 2019)7. Such plans are a crude expression of the same neoliberal policies that have ended up affecting virtually every country, weakening governments' health care services and, often, leaving much of the population with little access to any such service even in high-income countries (Labonté and Stuckler, 2015). To some extent, everybody is eventually affected by these policies, because contagious diseases cannot be eradicated just for certain social classes, and because such policies have resulted in a general weakening of health systems. The epidemiological Jevons' paradox compels health systems to develop continuously just to maintain the improvements that had already been achieved, but their capacity to respond to such requirement is curtailed by neoliberal policies. The results have become apparent during the COVID-19 pandemic. Even within the OECD, countries more affected by such policies display higher case-fatality rates (Sherpa, 2020), with health systems having to work under high stress and relying on extra, voluntary efforts by health personnel, unpaid caregivers and, to a lesser extent, citizenry in general.

\section{Policy proposal}

Considering that many potential pandemics are in the waiting list (Jones et al., 2008; Carlson et al., 2020) and they could be even more harmful than COVID-19 (Mermel, 2005), this section outlines a plan to prepare for and, if possible, prevent the next pandemic, based on scientific knowledge and equity. The plan is conceived as an international agreement to be adopted by governments, but the same basic principles could be applied also at other levels. It affects the economic activities most heavily involved in the origination, spread and cure of infectious diseases. To avoid the epidemiological Jevons' paradox, this plan involves a kind of wedge between activities that increase or reduce protection from infectious disease, to ensure that the former remain structurally ahead of the latter. Even if the paradox were disproved, the COVID-19 experience would suffice to concede that, for whatever reason, the balance between beneficial and detrimental activities is too tilted toward the latter, while the evidence given in sec. 3.1 would suffice to conclude that there is a deep distributive injustice behind such tilt, a twofold conclusion that would more than justify the kind of wedge introduced in this section.

The need of massive governments' investment to upgrade health systems in most countries, in anticipation of the next potential pandemic, would be denied by few people during the generalized lockdown under which this paper is being written. However, not only could it be unfeasible in many countries to fund all of this effort from, say, income or payroll taxes, but it would be unjust, because not everybody contributes equally to this risk. A straightforward consequence of the magnitude of the cost-shifting and the exceptional role of aviation (highlighted in sec. 3.1) is that a tax on aviation would be much fairer. Therefore, the first part of the proposal is the creation of a Global Pandemic Prevention and Preparedness Fund under the auspices of the United Nations, whose base funding would come from an internationally agreed tax on aviation.

\footnotetext{
${ }^{7}$ It has also been interpreted that such policies promote demographic growth (Sarkar, 1993), with the consequent environmental and epidemiological challenges.
} 
This Fund would serve to upgrade government-run or communitarian health systems (broadly defined, including all required mechanisms to monitor and respond to emerging infectious diseases). The Fund would also ensure the long-term continuity of such improvements, by providing regular, predictable funding (in view of the limitations demonstrated by current international aid due to its volatility; Ottersen et al., 2014). This would require mechanisms to hedge against possible financial downturns in the air transportation industry (requiring commitment from the governments of high-income countries).

A second function of the Fund would be to finance programs to prevent the emergence of new infectious diseases, focusing where such programs can be most cost-effective. This criterion would justify a special effort to tackle wild animal trade (sec. 2.4), besides programs in other areas, notably biosafety (sec. 2.5) (animal farming is addressed with a separate tool, below). Wildlife trade involves a high diversity of interacting actors, including major legal businesses 8 , criminal organizations, and local, marginalized communities (t Sas-Rolfes et al., 2019). A requirement for such programs to receive funding would be a careful design to take into account the livelihoods and preferences of the latter.

Let us consider the tax on aviation in more detail. This proposal relies on the supposition that airlines will become again a viable business. The tax would be additional to carbon and other taxes. It would be graded according to the distance flown, the degree of compliance with good practices (e.g., concerning illegal wildlife traffic; Utermohlen, 2019), and, in the case of passenger transportation, the frequency with which the passenger flies. The latter measure intends to attenuate potential downsides of a tax on aviation, such as even greater inequality in the access to air travel as a function of income, or a disproportionate impact on migrants who are currently living and working far from their families. A quantitatively detailed plan is beyond the scope of this paper, but some numbers are given for orientation. As noted, the estimated revenue of commercial airlines in 2019 was $\$ 838$ billion. The operating profit (before interests and taxes) was $\$ 42.5$ billion and the net profit $\$ 25$ billion (IATA, 2019b). Little before the COVID-19 pandemic, a report of the World Bank Group (WBG, 2019, p. 17) estimated the annual cost that would be needed for pandemic preparedness at $\$ 13$ billion, which is $50 \%$ of the airlines' net profit but only $1.6 \%$ of their revenue, so a relatively modest tax on aviation would suffice to cover this cost. Such a tax would also suffice, e.g., to have an impact on the level of international funding of the control of international wildlife trafficking, with major donors having committed less than $\$ 200$ million per annum (0.02\% of the airlines' revenue) in recent years (WBG, 2016), which however only covers a minor fraction of the needs (t Sas-Rolfes et al., 2019). However, a higher level of ambition would be desirable. A tax high enough to also serve to constrain long-haul air traffic is suggested (see below), besides supplementary funding from more conventional sources in case this does not suffice to cover all the needs. More clues about the potential of a tax on aviation: commercial airlines' net profits equal $40 \%$ of the health expenditure in countries where one fourth of the world's population lives, while the total health expenditures benefiting half the world's population equals $85 \%$ of the airlines' revenues, and the total revenues equal one third of the health expenditure devoted to $90 \%$ of the world's population 9

The tax on aviation would be high enough to constrain long-haul flights (in combination with

\footnotetext{
${ }^{8}$ As a complementary measure, new bans are pertinent for such business, such as those being currently implemented by some countries (CITES, 2020).

${ }^{9}$ These percentages were obtained by sorting countries by increasing GDP pc. Data for 2013 from UN (2020) and IATA (2019b).
} 
carbon taxes, whose impact, however, would be proportionally greater on short- and mediumhaul flights). At least, it would serve to constrain long-haul air traffic to pre-COVID-19 figures, because, should growth trajectories resume after the initial impact of this pandemic (with, e.g., the number of international passenger-kilometres flown having increased by $7.2 \%$ from 2017 to 2018 (IATA, 2019a), corresponding to a doubling every ten years), the possibility to control local epidemics before becoming pandemics would be increasingly elusive. Albeit a detailed assessment is pending, an even lower volume would probably be desirable. Since the epidemiological impact of the number of flights is not linear, a partial decrease in air traffic would have a modest impact on the timing of the dispersal of epidemics in their exponential phase (Bajardi et al., 2011). However, with health systems better funded and well prepared to detect emerging infectious diseases in their early stages, just a few days of delay would be precious time gained to notice the presence of the disease and take stronger action while it still affects a limited area. The benefit of combining less air travel with local containment has been modeled in the case of COVID-19 (Chinazzi et al, 2020). The tax would be expected to deter some prospect customers from traveling, while others would shift to other, slower means of transportation. Of course such modal changes do not avoid by themselves the spread of the disease, but, following the above logic, modest decreases in the speed of propagation can make a difference if combined with strong detection and response to emerging diseases (e.g., the disease could be detected on time for a ship crossing the ocean to be quarantined before reaching its destination) ${ }^{11}$. Indeed a policy of constraining flights would also bring substantial co-benefits for climate, permitting greater ambition in greenhouse gas emission targets, as well as in the sustainable use of resources, to levels that would have had much fewer options of being achieved without the early tasting of the consequences of unsustainability brought about by COVID-19.

Industrial animal farming compares to aviation both because of its key role in pandemic risk (sec. 2.3) and because of its financial turnover, thus deserving no less attention. Aside from the above Fund, another part of the multilateral agreement would consist of a calendar for each country to transform, in measurable steps, its agri-food system toward a sustainable and epidemiologically safe model. Among other measures, countries would strive to reduce the production and consumption of animal products (as emphasized by epidemiologists such as Kock et al., 2020) and, in the remaining livestock, to replace the use of antibiotics by healthier living conditions for the animals. Such changes would also bring major co-benefits for the local and global environment (including less pressure on ecosystems, with the corresponding epidemiological benefit; sec. 2.4), each country's food sovereignty, and the prevention of nontransmissible diseases (Willet et al., 2019) (not to mention animal welfare). Each country would be free to apply its own policies to achieve the agreed targets. Similarly to the case of airlines, taxes on industrial animal farming merit consideration. They are suggested as one of the main tools for governments to achieve their targets. However, the preferred use of these taxes is to benefit alternative agri-food schemes, in various ways, such as: grants and loans to producers and distributors aligned with the intended policies, financing the transition in others, research and assessment, and information campaigns for the general public about the various benefits of

\footnotetext{
${ }^{10}$ Should this possibility be envisaged, the sectors dependent on air travel would need assistance from governments and multilateral institutions for their conversion, rather than just to survive during the crisis.

${ }^{11}$ Therefore, mild diseases, for which no specific containment action would be taken, would propagate almost with the same ease, with some delay. It has been suggested that the propagation of such diseases might help to increase resistance to related but more virulent strains (Thompson et al., 2019).
} 
diet change and advices to carry it out. The differences between the kinds of taxes suggested for aviation and industrial animal farming are justified in Appendix B. This is a preferred option, but the fundamental need is to address these two key sectors seriously, whichever the specific policy.

The application of the described measures, even if very partially, would be a formidable advance. However, an even deeper transformation is urgently needed. In particular, ecosystem conservation and climate change mitigation would benefit from the suggested measures, but these measures do not cover and do not intend to cover these vast areas comprehensively. Ideally, these needs would be mainly covered by the reinforcement of already existing programs or the creation of other programs not addressed primarily to epidemiology, but if those happen to be insufficient to support projects of particular, strategic interest to prevent the emergence of new infectious diseases, these projects would clearly be eligible to benefit from the Fund under the already mentioned criterion of cost-effectiveness. Similarly, economic inequality and the undervaluation and precariousness of care work are vast areas in need of attention to prevent the propagation of infectious disease but also for many other reasons, and, obviously, they would not be covered comprehensively by the suggested measures alone, but the redistribution of funds to support health systems should contribute.

\section{Discussion}

The contemporary world has been described as a high-speed society, undergoing social acceleration (Rosa and Scheuerman, 2009), which, in the economic dimension, finds its expression in economic growth. The high intensity and long range of interactions is enabled by and enabler of economic growth (Bettencourt et al., 2007), by permitting coordinated activities, exchanges, and combination of resources from different origins. They also bring some nonmarket benefits, but involve high energy demand, failure to close material cycles, ecosystem impoverishment and homogenization, and mounting psychological loads. A high intensity and long range of interactions create, too, the perfect medium for infectious diseases to arise and become pandemics. Progresses in sanitation, medicine and health systems led the population of wealthy countries to mostly ignore pandemic threats (except for a few spikes of attention, e.g., following the initial spread of AIDS), until COVID-19 arrived and forced the high-speed society to brake. Even the radical green, degrowth and post-growth literature largely failed to mention pandemic risks alongside other environmental and social factors of unsustainability of the current economic model, but warnings of pandemic risk from this stance did exist (e.g., by the author of the present paper, first in Pueyo, 1998) and, more important, such warnings are just one more example of a fundamental criticism implicit in this literature: that an increasingly technified society where short-term growth imperatives and profit motives hold priority over the general long-term interest is doomed to disaster the sooner or the later. A basic hypothesis introduced in this paper, and supported by the various lines of evidence discussed in sec. 2, is that progresses in sanitation, medicine and health systems posed the basis not only for forgetting about diseases but also for growth in the very economic activities and structures that tend to cancel out such progresses, with health systems needing all the running you can do, to keep in the same place (sec. 1) given the massive cost-shifting, but failing to keep running as quickly as needed because of the neoliberal seizure of social, cultural, economic and political power. From this interpretation it follows that an event 
like the COVID-19 pandemic was highly plausible the sooner or the later, and materialized the accumulated cost-shifting from the economic activities that create pandemic risk to the rest of society.

Pandemic risks are not exhausted with COVID-19 (Jones et al., 2008; Carlson et al., 2020). The next pandemic could be even worse, perhaps causing even more mortality (Mermel, 2005) and not sharing the special feature of COVID-19 of being normally benign with children. From the notions of an epidemiological Jevons' paradox and of cost-shifting, it is straightforward to seek solutions along the lines of the already mentioned literatures which problematize economic growth (e.g., Kallis et al., 2018). Such literatures do not propose a kind of return to a past that lacked the current means to cure diseases, but to overcome growth-dependencies and keep economic activities at a sustainable level, allocating the available resources equitably and concentrating them in the functions that are really needed, such as health care. However, rather than advocating such generic principles, the goal of this paper, beyond the tentative diagnosis, is to present a specific plan to prepare for and, hopefully, prevent the next pandemic. Even if the case for an epidemiological Jevons' paradox (based on combining various pieces of partial evidence in the literature, and in need of more focused research) were found unconvincing, the policy proposal would remain valid, as argued in sec. 4. Furthermore, while the redistributive nature of the proposal was justified by appealing to the notion of cost-shifting (sec. 3.1) rather than externality, which, among other difficulties (Spash, 2019), would have carried the implication that epidemiological costs (including human lives) can be quantified in monetary units, the policy proposal would be consistent with neoclassical economics if re-framed as the internalization of an externality. The possibility of internalizing the cost of creating epidemic risk was briefly discussed by Singer (2005) and Perrings et al. (2018), which are thus important precedents. From a neoclassical stance it should be more difficult to argue against a policy of this kind than in favor.

Unfortunately, there are more antagonistic platforms competing to gain audience in this context of general disorientation. Some see in the current health crisis an opportunity for a xenophobe agenda. Given the role of people's movements around the world in disease propagation, there is risk of takeover by the extreme right, which is an extra reason to disseminate a sounder response to the problem quickly. Even from the strictly epidemiological point of view, there are at least two reasons why the proposal in this paper is sounder. First, high income, western countries are not minor sources of emergent infectious diseases: between 1940 and 2004, 100 such diseases were reported in the U.S. and a similar number in western Europe (Woolhouse, 2008) ${ }^{12}$. Fortunately, none of them spread like COVID-19, but this is a roulette. Second, the amount of migrants traveling from low-income to high-income countries often pales as compared to the number of local tourists and businesspeople coming back from journeys to these same low income countries. Rather than classifying people by their nationality, it would be more effective to limit the frequency or speed of travel, while addressing the factors that contribute to originating infectious diseases and reinforcing the means to cure them. Another platform, well positioned to become the new common sense with little discussion, calls for a chronification of

\footnotetext{
${ }^{12}$ Some diseases first detected in these countries might have originated elsewhere (Woolhouse, 2008), but, conversely, many if not most diseases originating in these (or any other) country are likely to go undetected. This is illustrated by studies showing that early cases of COVID-19 in some European countries were not identified as a new disease (Coma et al., 2020; Ceriani et al., 2020), even when they were causing, in several provinces, as much mortality as all other causes together (Ceriani et al., 2020).
} 
some dose of the currently needed social distancing (possibly accompanied by Orwellian surveillance methods, which do however spur discussion). This is just an instance of shifting corporate responsibilities to citizens (as previously described, e.g., in waste management; Wilkins, 2018). Furthemore, the ongoing social distancing is accompanied by a general upload of personal and professional lives to the Internet. While it is not questioned that, e.g., video-conferences are preferable to flights given the manifold impacts of the latter, it is problematic to generalize the adoption of digital alternatives to every real-world activity. The indiscriminate acceleration of a digital transformation shaped by market forces poses environmental, social, psychological and, ultimately, existential threats for which humanity is even less prepared than it used to be for a pandemic like COVID-19. However, humanity is on time to choose a different path, and the mental shake-up due to the pandemic creates a specially suitable occasion to rethink everything.

According to an old green aphorism, if today we don't do the impossible, tomorrow we will see the incredible $\left.\right|^{13}$. Unfortunately, we failed to do the impossible, tomorrow arrived, and we are witnessing the incredible. However, there is now a unique opportunity to prevent the next incredible by advancing policies that would normally be impossible. The positive side of incredible situations is that they can make the impossible turn possible.

\section{Appendix A: Share of the global population participating in international air travel}

Gössling et al. (2007) estimated that $<2 \%$ of the global population participated in international air travel in 2000. Given the rapid growth in air traffic in the period from 2000 to the onset of the COVID-19 pandemic (IATA, 2019a), this Appendix updates the estimate to 2018, which is the most recent year for which reliable data are available. IATA (2019a) registered 1,811,324 thousand international trips in that year. However, outgoing and return trips, as well as each of the connections, are counted as separate trips. Therefore, it is more straightforward to follow Gössling et al.'s (2007) methodology and work with the number of international tourist arrivals registered by UNWTO. This agency uses the definitions established by the UN (2010, p. 10), for which $A$ visitor (domestic, inbound or outbound) is classified as a tourist (or overnight visitor) if his/her trip includes an overnight stay and A visitor is a traveller taking a trip to a main destination outside his/her usual environment, for less than a year, for any main purpose (business, leisure or other personal purpose) other than to be employed by a resident entity in the country or place visited. Most international travelers are thus covered by this definition. Gössling et al. (2007) divided the number of international tourist arrivals by air in 2000 by the world population in that year and by 2.5 , which was the assumed average number of journeys per international traveler during the year. Even though most of the people who fly to some other country in any given year must do so only once, many journeys are due to a minority of high frequency travelers (Gössling et al., 2009; Liu et al., 2017), which justifies assuming an average frequency well above unity. Performing the same calculation for the 730,885,776 inbound international tourists that arrived by air in 2018 according to UNWTO (2020) and an estimated global population of 7,631,091,113 in that year (UN, 2019), the result would be 3.8\%. The obvious caveat is that this calculation assumes that all the growth in international air travel is concentrated in the

\footnotetext{
${ }^{13}$ Originally heard by the author in Catalan: Si avui no fem l'impossible, demà veurem l'increïble.
} 
extensive margin (number of people participating), ignoring possible changes in the intensive margin (number of journeys per traveler).

\section{Appendix B: Rationale for the differences in the suggested taxes for aviation and for industrial animal farming}

There are certain asymmetries between the tax on aviation and the tax on industrial animal farming suggested in sec. 4. One asymmetry is that the first would be global, while the second would be an optional tool for governments to comply with some given commitments. Another asymmetry concerns how the obtained funds would circulate among broad economic sectors (such as the transportation, agri-food or health sector). Both would be earmarked taxes, i.e., the funds would have predefined uses, but in the first case they would be transferred to a different sector, while in the second they would be reinvested in the same sector (a scheme with a long tradition in green programs; Riechmann, 1994). These two schemes have pros and cons. Only the first serves to cover a need for funding in other, essential areas. Furthermore, in so doing, the tax reduces the amount of cost-shifting. However, for the same reason, only the second prevents the possible built-up of a vested interest by governments to perpetuate the undesired practices that originate such costs, once these practices become the source of funding for necessary public services. Also, the first can help to constrain the volume of the taxed sector, while the second can be more effective to transform it. Related to this, the first would have a higher impact on the average consumers' prices of the products or services in the sector. The different choices in each case has the following rationale. Because of the nature of air transportation, it should be easier to globally agree on homogeneous taxing criteria and to supervise compliance from abroad. Given the strong international component of this activity, it should also be easier for the public and governments to accept the idea of the revenues of the tax being administered by a UN-dependent body and allocated according to the needs of each country rather than their contribution. If the taxes are homogeneous and administered by a UN body, there should be less interference of vested interests, because of the potentially higher transparency and the absence of the factor of economic competition among countries. Also, the impact sought on international aviation is not, in principle, complete phase-out (unlike industrial animal farming), but constraining air traffic to levels that are more manageable epidemiologically, which could be compatible with sustained revenues for the Fund. Furthermore, generally speaking, higher prices for air travel do not affect basic needs (especially if the prices are an increasing function of the frequency of flights). In contrast, for agri-food systems, with their partly local character and their heterogeneity, it would be more difficult to have globally homogeneous taxes supervised internationally, and their revenues used beyond the borders of each country. Also, a deep transformation of the sector is essential to minimize the collective costs that it generates, so this is a worthwhile use for the revenues of the tax, and if they ever cease to be available because the transformation is complete, anyway they will no longer be needed for this use. Furthermore, food is a basic need, so, as long as some kinds of food are taxed, it will be helpful to have funds available to reduce the price of other types of food and to assess consumers on diet changes. 


\section{Acknowledgments}

I am grateful, for useful inputs, to (in alphabetical order) Arnau Montserrat, Christos Zografos, Cristina O'Callaghan-Gordo, Ester Conesa-Carpintero, Filka Sekulova, François Schneider, Giacomo d'Alisa, Jean Boucher, Joan Martínez Alier, Marta Conde, Noèlia Arco, Panagiota Kotsila, Paul Peeters, Sam Bliss and Sílvia Heras.

\section{References}

Alcott, B., 2005. Jevons' paradox. Ecol. Econ. 54, 9-21.

Alirol, E., Getaz, L., Stoll, B., Chappuis, F., Loutan, L., 2011. Urbanisation and infectious diseases in a globalised world. Lancet. Infect. Dis. 11, 131-141.

Andersen, K.G., Rambaut, A., Lipkin, W.I., Holmes, E.C., Garry, R.F., 2020. The proximal origin of SARS-CoV-2. Nat. Med. 26, 450-452.

Anderson, R.M., May, R.M., 1979. Population biology of infectious diseases: Part I. Nature 280, 361-367.

Bajardi, P., Poletto, C., Ramasco, J.J., Tizzoni, M., Colizza, V., Vespignani, A., 2011. Human mobility networks, travel restrictions, and the global spread of 2009 H1N1 pandemic. PLoS ONE 6 , e16591.

Barham, A.R., Barham, B.L., Johnson, A.K., Allen, D.M., Blanton Jr., J.R., Miller, M.F., 2002. Effects of the transportation of beef cattle from the feedyard to the packing plant on prevalence levels of Escherichia coli O157 and Salmonella spp. J. Food Prot. 65, 280-283.

Bar-On, Y.M., Phillips, R., Milo, R., 2018. The biomass distribution on Earth. Proc. Natl. Acad. Sci. USA 25, 6506-6511.

Blech, F., Pollman, D.S., Nichols, D.A., 1983. Weaning pigs at an early age decreases cellular immunity. J. Anim. Sci. 56, 396-400.

Bettencourt, L.M.A., Lobo, J., Helbing, D., Kühnert, C., West, G.B., 2007. Growth, innovation, scaling, and the pace of life in cities. Proc. Natl. Acad. Sci. USA 104, 7301-7306.

Boqvist, S., Dekker, A., Depner, K., Grace, D., Hueston, W., Stärk, K.D.C., Sternberg Lewerin, S., 2014. Contagious animal diseases: The science behind trade policies and standards. Vet. J. $202,7-10$.

Carlson, C.J., Albery, G.F., Merow, C., Trisos, C.H., Zipfel, C.M., Eskew, E.A., Olival, K.J., Ross, N., Bansal, S., 2020. Climate change will drive novel cross-species viral transmission. 
bioRxiv, doi: 10.1101/2020.01.24.918755.

Ceriani, L., Hernandez-Suarez, C., Verme, P., 2020. A simple early warning signal for COVID19. medRxiv, doi: 10.1101/2020.04.28.20083261.

Chinazzi, M., Davis, J.T., Ajelli, M., Gioannini, C., Litvinova, M., Merler, S., Pastore y Piontti, A., Mu, K., Rossi, L., Sun, K., Viboud, C., Xiong, X., Yu, H., Halloran, E., Longini Jr., I.M., Vespignani, A., 2020. The effect of travel restrictions on the spread of the 2019 novel coronavirus (COVID-19) outbreak. Science 368, 395-400.

CITES (Convention on International Trade in Endangered Species of Wild Fauna and Flora), 2020. Notification to the Parties No. 2020/018. CITES Secretariat, Geneva.

Cohn, S., 2008. 4 Epidemiology of the Black Death and successive waves of plague. Med. Hist. $52,74-100$.

Coma, E., Mora, N., Prats-Uribe, A., Fina, F., Prieto-Alhambra, D., Medina-Peralta, M., 2020. Excess cases of influenza suggest an earlier start to the coronavirus epidemic in Spain than official figures tell us: an analysis of primary care electronic medical records from over 6 million people from Catalonia. medRxiv, doi: 10.1101/2020.04.09.20056259.

Decaestecker, E., King, K. 2019. Red Queen dynamics, in: Fath. B. (Ed.), Encyclopedia of Ecology, second ed., vol 3. Elsevier, Amsterdam, pp. 185-195.

Dobson, A.P., Carper, E.R., 1996. Infectious diseases and human population history. BioScience 46, 115-126.

Dong, E., Du, H., Gardner, L., 2020. An interactive web-based dashboard to track COVID-19 in real time. Lancet. Infect. Dis. 20, 533-534.

ECDC (European Centre for Disease Prevention and Control), EMEA (European Medicines Agency), 2009. The Bacterial Challenge: Time to React. ECDC/EMEA, Stockholm.

FAO, 2006. Livestock's Long Shadow. Environmental Issues and Options. FAO, Rome.

Fearnside, P.M., 2017. Deforestation of the Brazilian Amazon, in: Shugart, H. (Ed.), Oxford Research Encyclopedia of Environmental Science. Oxford University Press, New York, doi: 10.1093/acrefore/9780199389414.013.102.

Forster, T., Kentikelenis, A.E, Stubbs, T.H., King, L.P., 2019. Globalization and health equity: The impact of structural adjustment programs on developing countries. Soc. Sci. \& Med., doi: 10.1016/j.socscimed.2019.112496.

Frick, W.F., Puechmaille, S.J., Hoyt, J.R., Nickel, B.A., Langwig, K.E., Foster, J.T., Barlow, 
K.E., Bartonička, T., Feller, D., Haarsma, A.J., Herzog, C., Horáček, I., van der Kooij, J., Mulkens, B., Petrov, B., Reynolds, R., Rodrigues, L., Stihler, C.W., Turner, G.G., Kilpatrick, A.M. 2015. Disease alters macroecological patterns of North American bats. Glob. Ecol. Biogeogr. 24, 741-749.

Gómez, J.M., Verdú, M., 2017. Network theory may explain the vulnerability of medieval human settlements to the Black Death pandemic. Sci. Rep. 7, 43467.

Gössling S, Broderick J, Upham P, Ceron, J.-P., Dubois, G., Peeters, P., Strasdas, W., 2007. Voluntary carbon offsetting schemes for aviation: Efficiency, credibility and sustainable tourism. J. Sustain. Tour. 15, 223-248.

Gössling, S., Ceron, J.-P., Dubois, G., Hall, C.M., 2009. Hypermobile travellers, in: Gössling, S., Upham, P. (Eds.), Climate Change and Aviation. Earthscan, New York.

Graham, A., Metz, D., 2017. Limits to air travel growth: The case of infrequent flyers. J. Air Transp. Manag. 62, 109-120.

Gray, G.C., Merchant, J.A., 2018. Pigs, pathogens, and public health. Lancet Infect. Dis. 18, 372-373.

Green, M.S., LeDuc, J., Cohen, D., Franz, D.R., 2019. Confronting the threat of bioterrorism: realities, challenges, and defensive strategies. Lancet Infect. Dis. 19, e2-13.

Hanlon, W.W., Tian, Y., 2015. Killer cities: Past and present. Am. Econ. Rev. 105, 570-575.

Hickel, J., 2017. The Divide. A Brief Guide to Global Inequality and its Solutions. Penguin Random House, London.

Holmes, A.H., Moore, L.S.P., Sundsfjord, A., Steinbakk, M., Regmi, S., Karkey, A., Guerin, P.J., Piddock, L.J.V., 2016. Understanding the mechanisms and drivers of antimicrobial resistance. Lancet 387, 176-187.

HRW (Human Rights Watch), 2020. India: COVID-19 Lockdown Puts Poor at Risk. https:// www . hrw.org/news/2020/03/27/india-covid-19-lockdown-puts-poor-risk (accessed 7 May 2020).

IATA (International Air Transport Association), 2019a. WATS: World Air Transport Statistics 2019. IATA, Geneva. https://www.iata.org/contentassets/a686ff624550453e8bf0c9b3f7f 0ab26/ wats-2019-mediakit.pdf (accessed 26 April 2020).

IATA (International Air Transport Association), 2019b. Industry Statistics Fact Sheet. December 2019. IATA, Geneva. https://www.iata.org/en/iata-repository/publications/ economic-reports/fact-sheet-industry-statistics-dec19.pdf (accessed 26 April 2020). 
IPBES (Intergovernmental Science-Policy Platform on Biodiversity and Ecosystem Services), 2019. Summary for policymakers of the global assessment report on biodiversity and ecosystem services of the Intergovernmental Science-Policy Platform on Biodiversity and Ecosystem Services. IPBES secretariat, Bonn.

IPCC (Intergovernmental Panel on Climate Change), 2019. Climate Change and Land. IPCC, Geneva.

Isidore, C., 2020. United, JetBlue cutting US flights because of coronavirus. CNN Business, March 5, 2020. https://edition.cnn.com/2020/03/04/business/united-us-flight-cutscoronavirus/index.html (accessed 16 April 2020).

Jedwab, R., Christiaensen, L., Gindelsky, M., 2015. Demography, Urbanization and Development. Rural Push, Urban Pull and... Urban Push? Policy Research Working Paper 7333. World Bank Group, Washington.

Johnson, C.K., Hitchens, P.L., Pandit, P.S., Rushmore, J., Evans, T.S., Young, C.C.W., Doyle, M.M., 2020. Global shifts in mammalian population trends reveal key predictors of virus spillover risk. Proc. R. Soc. B 287, 20192736.

Jones, K.E., Patel, N.G., Levy, M.A., Storeygard, A., Balk, D., Gittleman, J.L., Daszak, P., 2008. Global trends in emerging infectious diseases. Nature 451, 990-993.

Kallis, G., Kostakis, V., Lange, S., Muraca, B., Paulson, S., Schmelzer, M., 2018. Research On Degrowth. Annu. Rev. Environ. Resour. 43, 291-316.

Kan, B., Wang, M., Jing, H., Xu, H., Jiang, X., Yan, M., Liang, W., Zheng, H., Wan, K., Liu, Q., Cui, B., Xu, Y., Zhang, E., Wang, H., Ye, J., Li, G., Li, M., Cui, Z., Qi, X., Chen, K., Du, L., Gao, K., Zhao, Y.-t., Zou, X.-z., Feng, Y.-J., Gao, Y.,-F., Hai, R., Yu, D., Guan, Y., Xu, J., 2005. Molecular evolution analysis and geographic investigation of severe acute respiratory syndrome coronavirus-like virus in palm civets at an animal market and on farms. J. Virol. 79, 1189211900.

Kapp, K. W. 1978 [1963]. The Social Costs of Business Enterprise (revised and extended edition). Spokesman, Nottingham.

Kock, R.A., Karesh, W.B., Veas, F., Velavan, T.P., Simons, D., Mboera, L.E.G., Dar, O., Arruda, L.B., Zumla, A., 2020. 2019-nCoV in context: lessons learned? Lancet Planet. Health 4, e87-e88.

Labonté, R., Stuckler, D., 2019. The rise of neoliberalism: how bad economics imperils health and what to do about it. J. Epidemiol. Community Health, doi:10.1136/jech-2015-206295.

Laxminarayan, R., Matsoso, P., Pant, S., Brower, C., Røttingen, J.-A., Klugman, K., Davies, S., 2016. Access to effective antimicrobials: A worldwide challenge. Lancet 387, 168-175. 
Legendre, M., Lartigue, A., Bertaux, L., Jeudy, S., Bartoli, J., Lescot, M., Alempic, J.-M., Ramus, C., Bruley, C., Labadie, K., Shmakova, L., Rivkina, E., Couté, Y., Abergel, C., Claverie, J.-M., 2015. In-depth study of Mollivirus sibericum, a new 30,000-y-old giant virus infecting Acanthamoeba. Proc. Natl. Acad. Sci. USA 112, E5327-E5335.

Liu, J., Liu, B., Liu, Y., Chen, H., Feng, L., Xiong, H., Huang, Y., 2017. Personalized air travel prediction: A multi-factor perspective. ACM Trans. Intell. Syst. Technol. 9, 30.

MacDonald, A.J., Mordecai, E.A., 2019. Amazon deforestation drives malaria transmission, and malaria burden reduces forest clearing. Proc. Natl. Acad. Sci. USA 116, 22212-22218.

Meirelles Filho, J., 2004. O Livro de Ouro da Amazônia, fourth ed. Ediouro, Rio de Janeiro.

Mermel, L.A., 2005. Pandemic avian influenza. Lancet Infect. Dis. 5, 666-667.

Ottersen, O.P., Dasgupta, J., Blouin, C., Buss, P., Chongsuvivatwong, V., Frenk, J., FukudaParr, S., Gawanas, B.P., Giacaman, R., Gyapong, J., Leaning, J., Marmot, M., McNeill, D., Mongella, G.I., Moyo, N., Møgedal, S., Ntsaluba, A., Ooms, G., Bjertness, E., Lie, A.L., Moon, S., Roalkvam, S., Sandberg, K.I., Scheel, I.B., 2014. The political origins of health inequity: prospects for change. The Lancet-University of Oslo Commission on Global Governance for Health. Lancet 383, 630667.

Pearce, B., 2020a. COVID-19: Updated Impact Assessment (14th April 2020). IATA, Geneva. https://www.iata.org/en/iata-repository/publications/economic-reports/covid-fourthimpact-assessment/ (accessed 26 April 2020).

Pearce, B., 2020b. COVID-19: Assessing Prospects for Domestic Markets (21sr April 2020). IATA, Geneva. https://www.iata.org/en/iata-repository/publications/economic-reports/ covid-19-assessing-prospects-for-domestic-markets/(accessed 26 April 2020).

Perrings, C., Levin, S., Daszak, P., 2018. The economics of infectious disease, trade and pandemic risk. EcoHealth 15, 241-243.

Poore, J., Nemecek, T., 2018. Reducing foods environmental impacts through producers and consumers. Science 360, 987-992.

Pruessner, G., 2012. Self-Organised Criticality. Cambridge Univ. Press, Cambridge.

Pueyo, S., 1998. Gérmenes sin fronteras. Integral 220, 44-49. https://ecoecophys.files. wordpress.com/2020/03/pueyo-1998-gc3a9rmenes-sin-fronteras.pdf

Pueyo, S., 2014. Ecological econophysics for degrowth. Sustainability 6, 3431-3483. 
Rhodes, C.J., Jensen, H.J., Anderson, R.M., 1997. On the critical behaviour of simple epidemics. Proc. R. Soc. Lond. B 264, 1639-1646.

Richters, O., Siemoneit, A., 2019. Growth imperatives: Substantiating a contested concept. Struct. Chang. Econ. Dyn. 51, 126-137.

Riechmann, J., 1994. Otra forma de trabajar, producir y consumir: Los programas económicos de Die Grünen. Ecología Política 6, 59-90.

Rohr, J.R., Barrett, C.B., Civitello, D.J., Craft, M.E., Delius, B., DeLeo, G.A., Hudson, P.J., Jouanard, N., Nguyen, K.H., Ostfeld, R.S., Remais, J.V., Riveau, G., Sokolow, S.H., Tilman, D., 2019. Emerging human infectious diseases and the links to global food production. Nat. Sustain. $2,445-456$.

Rosa, H., Scheuerman, W.E. (Eds.), 2009. High-Speed Society. Social Acceleration, Power, and Modernity. Pennsilvania State Univ. Press.

Rulli, M.C., Santini, M., Hayman, D.T.S., D’Odorico, P., 2017. The nexus between forest fragmentation in Africa and Ebola virus disease outbreaks. Sci. Rep. 7, 41613.

Sarkar, S., 1993. Una síntesis ecosocialista del problema de la sobrepoblación. Ecología Política 6,143152 .

Schmid, B.V., Büntgen, U., Easterday, W.R., Ginzler, C., Walløe, L., Bramanti, B., Stenseth, N.C., 2015. Climate-driven introduction of the Black Death and successive plague reintroductions into Europe. Proc. Natl. Acad. Sci. USA 112: 3020-3025.

Schader, C., Muller, A., Scialabba, N.E-H., Hecht, J., Isensee, A., Erb, K.-H., Smith, P., Makkar, H.P.S., Klocke, P., Leiber, F., Schwegler, P., Stolze, M., Niggli, U., 2015. Impacts of feeding less food-competing feedstuffs to livestock on global food system sustainability. J. R. Soc. Interface 12, 20150891.

Schneider, F., 2008. Macroscopic rebound effects as argument for economic degrowth. Proceedings of the First International Conference on Economic De-growth for Ecological Sustainability and Social Equity, Paris, April 18-19th 2008. https://www.researchgate.net/profile/ Francois_Schneider2/publication/288665925_Macroscopic_rebound_effects_as_argument. for_economic_degrowth/links/5e6a7553458515e555762c6e/Macroscopic-rebound-effects;as-argument-for-economic-degrowth.pdf

Sherpa, D., 2020. Estimating impact of Austerity policies in COVID-19 fatality rates: Examining the dynamics of economic policy and Case Fatality Rates (CFR) of COVID-19 in OECD countries. medRxiv, doi: 10.1101/2020.04.03.20047530.

Singer, P., 2005. Who pays for bird flu? Project Syndicate, November 2005. http://www. 
project-syndicate.org/commentary/singer5 (accessed 24 June 2020).

Spash, C.L., 2019. Making pollution into a market failure rather than a cost-shifting success: The suppression of revolutionary change in economics. SRE - Discussion Papers 2019/06. WU Vienna University of Economics and Business, Vienna. http://www-sre.wu.ac.at/sre-disc/sredisc-2019_06.pdf

Stier, A.J., Berman, M.G., Bettencourt, L.M.A., 2020. COVID-19 attack rate increases with city size. arXiv:2003.10376v2 [q-bio.PE].

Storey, R., 1985. An estimate of mortality in a pre-Columbian urban population. Am. Anthropol. $87,519-535$.

't Sas-Rolfes, M., Challender, D.W.S., Hinsley, A., Veríssimo, D., Milner-Gulland, E.J., 2019. Illegal wildlife trade: Scale, processes, and governance. Annu. Rev. Environ. Resour. 44, 201-28.

Thompson, R.N., Thompson, C.P., Pelerman, O., Gupta, S., Obolski, U., 2019 . Increased frequency of travel in the presence of cross-immunity may act to decrease the chance of a global pandemic. Phil. Trans. R. Soc. B 374, 20180274.

UN (United Nations), 2010. International Recommendations for Tourism Statistics 2008. UN, New York.

UN (United Nations), 2019. World Population Prospects 2019, Online Edition. Rev. 1. UN, New York. https://population.un.org/wpp/ (accessed 26 April 2020).

UN (United Nations), 2020. UNdata. UN, New York. https://data.un.org/ (accessed 29 April 2020).

UNWTO (World Tourism Organization), 2020. Compendium of Tourism Statistics dataset [Electronic] (updated on 20 January 2020). UNWTO, Madrid. https://www.unwto.org/ data(accessed27Apri12020).

Utermohlen, M., 2019. Runway to Extinction. Wildlife Trafficking in the Air Transport Sector. C4ADS, Washington.

Vogel, H.L., 2016. Travel Industry Economics, third ed. Springer.

Walter, B.S., DeWitte, S.N., 2017. Urban and rural mortality and survival in Medieval England. Ann. Hum. Biol. 44, 338-348.

Wang L., Wu, J.T., 2018. Characterizing the dynamics underlying global spread of epidemics. Nat. Commun. 9: 218. 
WBG (World Bank Group), 2016. Analysis of International Funding to Tackle Illegal Wildlife Trade. World Bank Group, Washington.

WBG (World Bank Group), 2019. Pandemic Preparedness Financing. Status Update. World Bank Group, Washington.

Wielinga, P.R., Jensen, V.F., Aarestrup, F.M., Schlundt, J., 2014. Evidence-based policy for controlling antimicrobial resistance in the food chain in Denmark. Food Control 40, 185-192.

Willett, W., Rockström, J., Loken, B., Springmann, M., Lang, T., Vermeulen, S., Garnett, T., Tilman, D., DeClerck, F., Wood, A., Jonell, M., Clark, M., Gordon, L. J., Fanzo, J., Hawkes, Zurayk, R., Rivera, J. A., De Vries, W., Majele Sibanda, L., Afshin, A., Chaudhary, A., Herrero, M., Agustina, R., Branca, F., Lartey, A., Fan, S., Crona, B., Fox, E., Bignet, V., Troell, M., Lindahl, T., Singh, S., Cornell, S. E., Srinath Reddy, K., Narain, S., Nishtar, S. and Murray, C.J.L., 2019. Food in the Anthropocene. The EAT-Lancet Commission on Healthy Diets from Sustainable Food Systems. Lancet 393, 447-492.

Williamson, G.J., 1990. Coping with City Growth during the British Industrial Revolution, Cambridge Univ. Press, Cambridge.

Wolfe, N.D., Dunavan, C.P., Diamond, J., 2007. Origins of major human infectious diseases. Nature 447, 279-283.

Woolhouse, M.E.J., 2008. Emerging diseases go global. Nature 451, 898-899.

Wu, J., 2016. Detection and attribution of the effects of climate change on bat distributions over the last 50 years. Clim. Ch. 134, 681-696.

Wu, T., Perrings, C., Shang, C., Collins, J.P., Daszak, P., Kinzig, A., Minteer, B.A., 2020. Protection of wetlands as a strategy for reducing the spread of avian influenza from migratory waterfowl. Ambio 49, 939-949.

Xue, J., 2014. Is eco-village/urban village the future of a degrowth society? An urban planner's perspective. Ecol. Econ. 105, 130-138.

- Preprint uploaded 17 July 2020 (first version uploaded 12 May 2020) - 